\section{SANDIA REPORT}

SAND97-0666 • UC-900

Unlimited Release

Printed April 1997
-

MAY O 61997

OSTI

\title{
Introduction to Technology Roadmapping: The Semiconductor Industry Association's Technology Roadmapping Process
}

Marie L. Garcia

Prepared by

Sandia National Laboratories

Albuquerque, New Mexico 87185 and Livermore, California 94550

Sandia is a multiprogram labótatory operated bySandia Corporation a Lockheed Martin Company, for the United States Department of

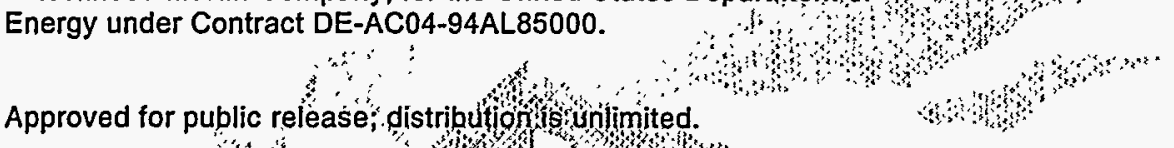

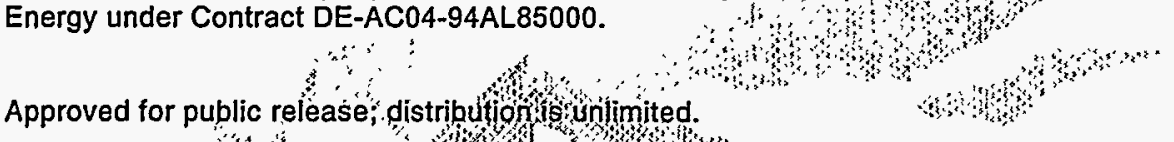
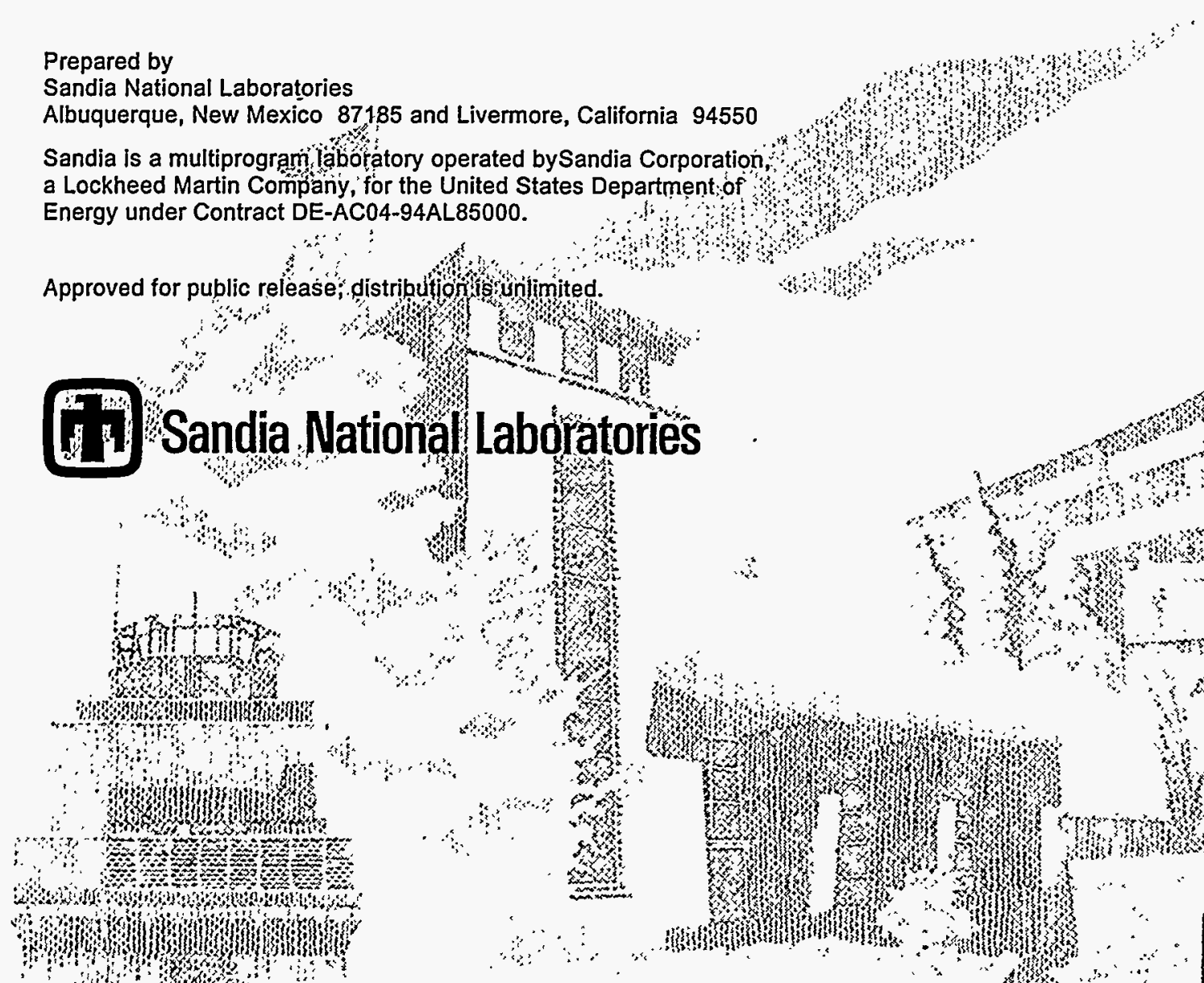

sing

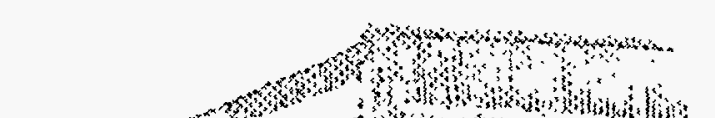

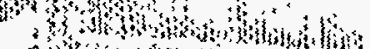


Issued by Sandia National Laboratories, operated for the United States Department of Energy by Sandia Corporation.

NOTICE: This report was prepared as an account of work sponsored by an agency of the United States Government. Neither the United States Government nor any agency thereof, nor any of their employees, nor any of their contractors, subcontractors, or their employees, makes any warranty, express or implied, or assumes any legal liability or responsibility for the accuracy, completeness, or usefulness of any information, apparatus, product, or process disclosed, or represents that its use would not infringe privately owned rights. Reference herein to any specific commercial product, process, or service by trade name, trademark, manufacturer, or otherwise, does not necessarily constitute or imply its endorsement, recommendation, or favoring by the United States Government, any agency thereof, or any of their contractors or subcontractors. The views and opinions expressed herein do not necessarily state or reflect those of the United States Government, any agency thereof, or any of their contractors.

Printed in the United States of America. This report has been reproduced directly from the best available copy.

Available to $\mathrm{DOE}$ and $\mathrm{DOE}$ contractors from

Office of Scientific and Technical Information

P.O. Box 62

Oak Ridge, TN 37831

Prices available from (615) 576-8401, FTS 626-8401

Available to the public from

National Technical Information Service

U.S. Department of Commerce

5285 Port Royal Rd

Springfield, VA 22161

NTIS price codes

Printed copy: A04

Microfiche copy: A01 


\section{DISCLAIMER}

This report was prepared as an account of work sponsored by an agency of the United States Government. Neither the United States Government nor any agency thereof, nor any of their employees, make any warranty, express or implied, or assumes any legal liability or responsibility for the accuracy, completeness, or usefulness of any information, apparatus, product, or process disclosed, or represents that its use would not infringe privately owned rights. Reference herein to any specific commercial product, process, or service by trade name, trademark, manufacturer, or otherwise does not necessarily constitute or imply its endorsement, recommendation, or favoring by the United States Government or any agency thereof. The views and opinions of authors expressed herein do not necessarily state or reflect those of the United States Government or any agency thereof. 


\section{DISCLAMIER}

Portions of this document may be illegible in electronic image products. Images are produced from the best available original document.

$\because$ 


\title{
Introduction to Technology Roadmapping: The Semiconductor Industry Association's Technology Roadmapping Process
}

\author{
Marie L. Garcia \\ Strategic Business Development Department \\ Sandia National Laboratories \\ P.O. Box 5800 \\ Albuquerque, NM 87185-1378
}

\begin{abstract}
A technology roadmap is the result of a strategic technology planning process that cooperatively identifies (1) a particular industry's common product and process performance targets, (2) the technology alternatives and milestones for meeting these targets, and (3) a common technology path for research and development activities. The author describes a successful major roadmapping experience - the Semiconductor Industry Association's Technology Roadmapping Process, which culminated in a workshop held in 1992. The report explains the committee structure and processes that were used both before and after the workshop and presents principles and practices that can aid future technology roadmappers. Appendix 1 summarizes the process from a committee-structure viewpoint. Appendix 2 summarizes the process from a functional viewpoint. Appendix 3 answers some frequently asked questions about technology roadmapping.
\end{abstract}


Intentionally Left Blank 


\section{Contents}

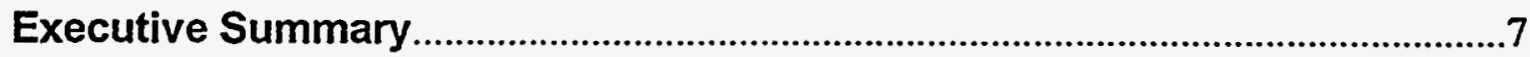

1. Introduction to Technology Roadmapping

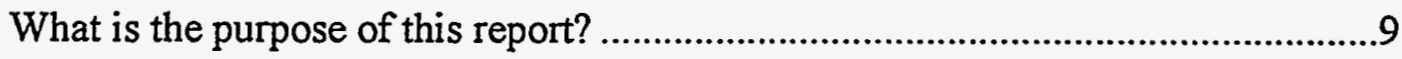

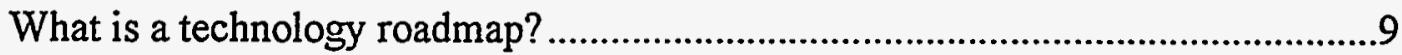

Conceptual stage of technology roadmapping ...................................................10

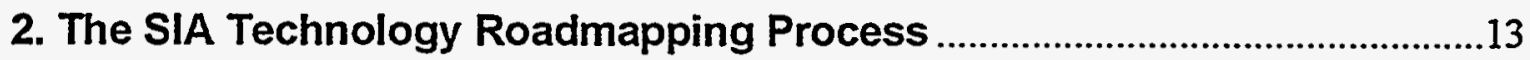

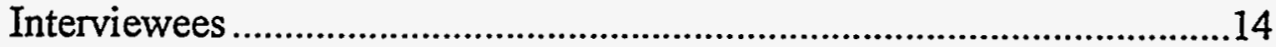

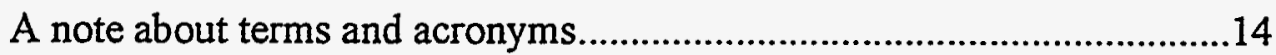

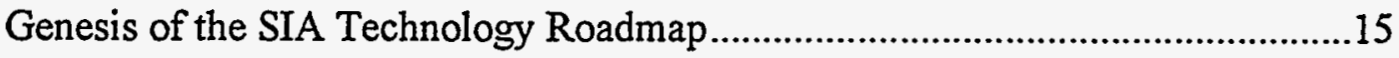

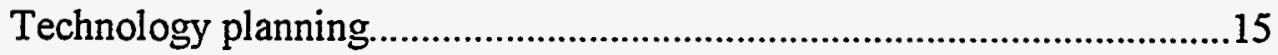

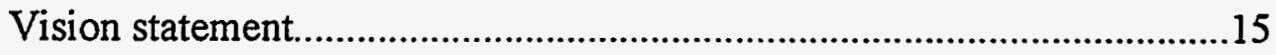

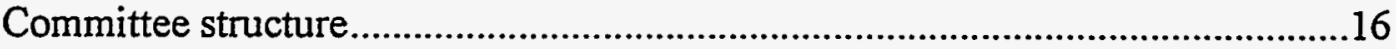

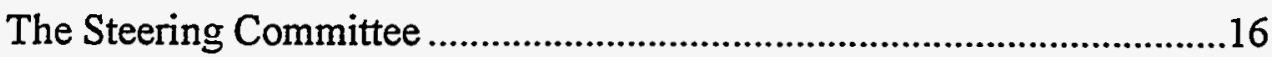

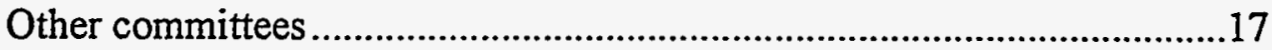

Planning the Roadmap Process: technology areas..............................................18

Steering Committee planning..............................................................18

Choosing members of technology working groups .................................19

Preparing the working groups.................................................................19

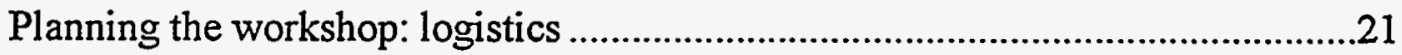

Financial arrangements ......................................................................22

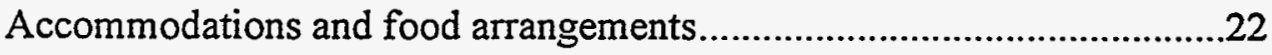

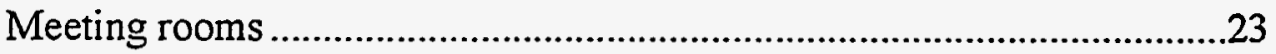

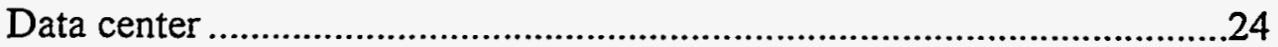

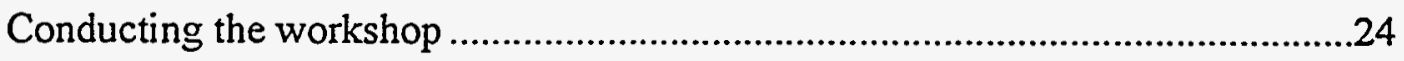

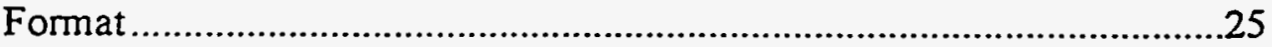

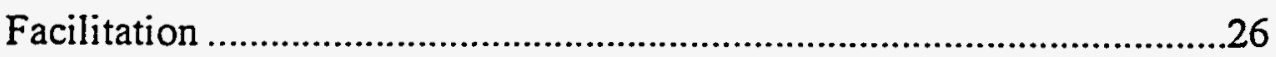

Other communication/interaction procedures..........................................26

Preparing draft conclusions, recommendations, and roadmaps .............................27

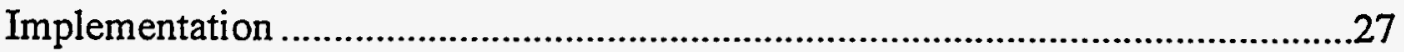

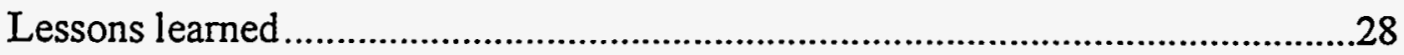

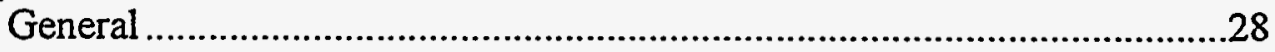

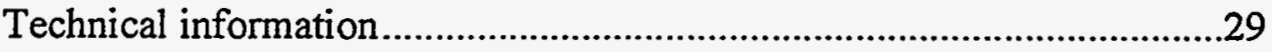

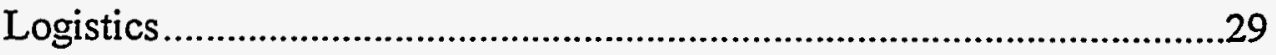

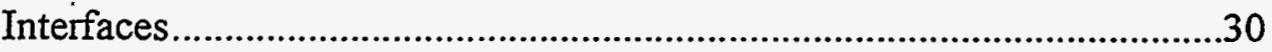

Refining the Technology Roadmapping Process................................................30 
(Contents, continued)

Appendix 1. SIA Technology Roadmapping Process -

Committee-Structure Viewpoint.............................................................

A. Necessary preexisting conditions ..................................................................31

B. Industry association/consortia should establish Steering

Committee six months before roadmap workshop date.....................................31

C. Steering Committee assumes many responsibilities ...........................................31

D. Steering Committee establishes committee structure ......................................32

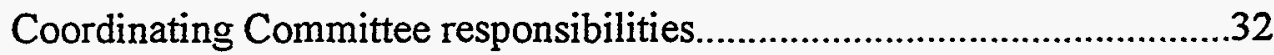

Framework Committee responsibilities ....................................................33

Implementation Committee responsibilities ..............................................33

Technology Committee responsibilities....................................................33

Logistics Committee responsibilities .......................................................33

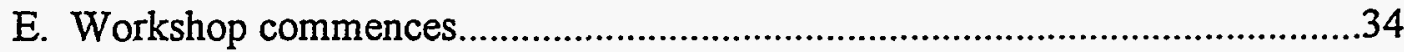

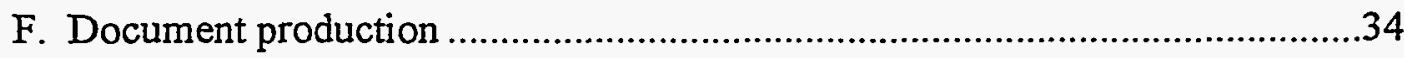

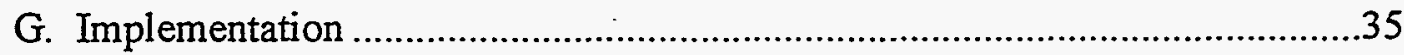

Appendix 2. SIA Technology Roadmapping Process -

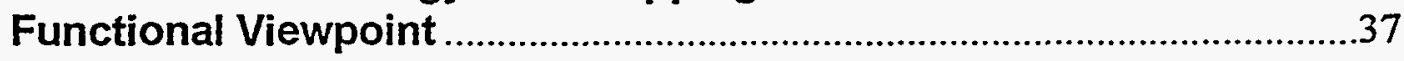

A. Determine necessary preexisting conditions..................................................37

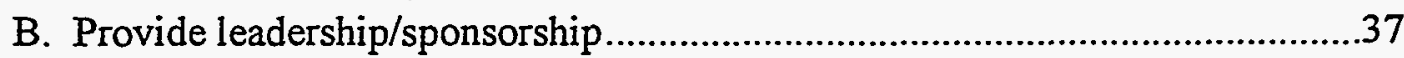

C. Establish high-level "whats" that need to be done...........................................37

D. Establish detailed "whats" that need to be done ..............................................38

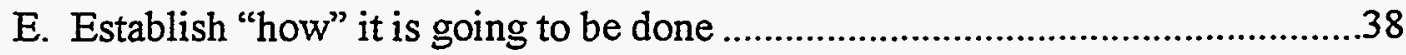

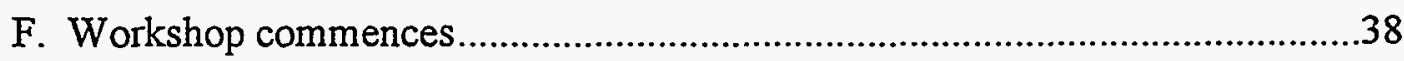

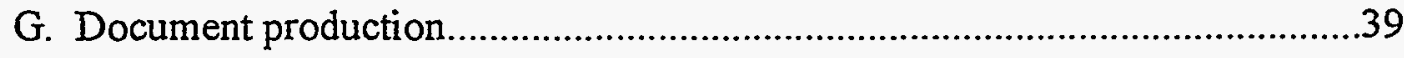

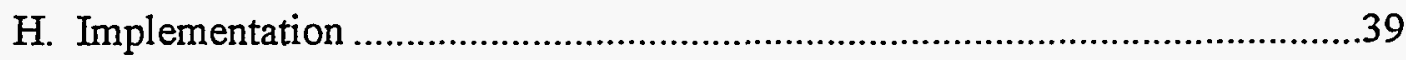

Appendix 3. Frequently Asked Questions about Technology

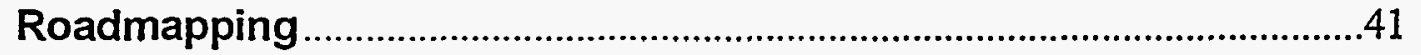

Appendix 4. Interconnect Working Group Pre-workshop

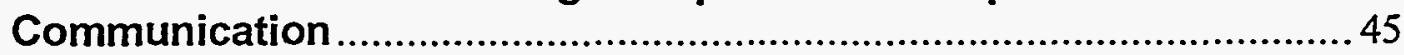

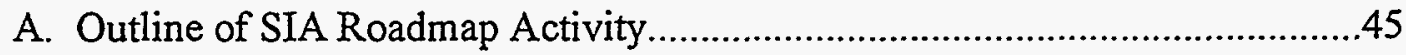

B. Interconnect Working Group Agenda for Workshop....................................47

C. Working group discussion guidelines ..........................................................49

Appendix 5. SIA Technology Roadmap Workshop Committee Flowchart Diagram................................................................................ 51 


\section{Executive Summary}

As a national security laboratory with a strong technology component, Sandia must do effective technology planning to identify and develop the technologies required to meet its mission. In an attempt to increase the author's knowledge of different technology planning processes and consequently provide more value to Sandia organizations wishing to develop strategic technology plans, a study of the SIA (Semiconductor Industry Association) Technology Roadmapping process was undertaken. The SIA Technology Roadmap was heralded as the model industry roadmap and therefore an excellent example for the author's initial research to understand technology roadmapping and the process for developing a technology roadmap.

Technology Roadmapping is a strategic technology planning process that helps industry and others envision the future, builds on known needs and technology capabilities, and creates a shared understanding of technology development challenges. The result of that process is a technology roadmap or collection of roadmaps that identify a particular industry's common product and process performance targets, the technology alternatives and milestones for meeting these targets, and a common technology path for research and development activities.

This report explains the SIA's successful major technology roadmapping experience, which culminated in a workshop held in 1992. It details the committee structure and processes that were used both before and after the workshop and presents principles and practices that can aid future technology roadmappers.

As a result of the Technology Roadmapping Workshop, two Semiconductor Industry Association (SIA) documents were published:

- Semiconductor Industry Association, 1993, Semiconductor Technology Workshop Working Group Reports. SIA, San Jose, CA.

- Semiconductor Industry Association, 1993, Semiconductor Technology Workshop Conchisions. SIA, San Jose, CA.

A third document was published, which updates the above two reports:

- Semiconductor Industry Association, 1994, The National Technology Roadmap for Semiconductors. SIA, San Jose, CA.

For more information, or to order additional copies of the above SIA Technology Roadmap documents, contact:

SEMATECH

Customer Service

2706 Montopolis Drive

Austin, TX 78741-6499

(512) $356-7421$ 
Intentionally Left Blank 


\section{Introduction to Technology Roadmapping: The Semiconductor Industry Association's Technology Roadmapping Process}

\section{Introduction to Technology Roadmapping}

Technology roadmapping is a strategic technology planning process that

- helps industry and others envision the future.

- builds on known needs and technology capabilities.

- creates a shared understanding of technology development challenges.

\section{What is the purpose of this report?}

This report documents the author's initial research to understand technology roadmapping and the process for developing a technology roadmap. Although there are different types of roadmaps, this report focuses only on industry-level technology roadmapping.

To learn about the technology roadmapping process, the author chose to study the SIA (Semiconductor Industry Association) Technology Roadmap, which was heralded as the model industry roadmap. However, the SIA Technology Roadmap was a result, not a specific process. Therefore, the author tried to identify the process through a series of interviews with key participants in the SIA roadmapping effort. They described the activities and sequences of events in which they participated. This report both documents the results of those interviews and tries to integrate the activities into a well-defined process.

\section{What is a technology roadmap?}

A technology roadmap is the result of a strategic technology planning process that cooperatively identifies common product and process performance targets, the technology alternatives and milestones for meeting these targets, and a common technology plan (path) for R\&D activities. 
A technology roadmap is done for a specific product or product family. It builds consensus on and specifies the features the product must provide at various points in the future. It then identifies the alternative technologies that would be able to meet these product milestones. The participants can then select the set of technology alternatives to be developed to satisfy the product requirements.

In summary, the technology roadmapping process builds a consensus on a critical set of product needs and the technology paths to satisfy them. Based on participant interviews, this report describes the committee structure and processes that were used to develop the SIA roadmap.

\section{Conceptual stage of technology roadmapping}

Pre-existing conditions that must be present for an industry to successfully develop and implement technology roadmaps include the following:

- A perceived need must exist to pull people together to develop roadmaps.

- The roadmap development should be "needs" driven, as opposed to being "a solution looking for a problem."

- Five parties must be involved: industry, government, suppliers, customers, and universities.

- Adversarial conditions must not exist between the producers and the suppliers; if they do, you will have a marginal condition.

- Some kind of industry umbrella is needed - without an industry association or a consortium, roadmap development and implementation would be difficult.

- The consortium needs to be able to decide exactly why it wants a roadmap and determine the boundary conditions. (Boundaries need to provide a framework, but not stop innovation.)

Developing technology roadmaps is a way of picking winners and losers of technologies, not companies. Industry and government can no longer afford to fund research as they have in the past. They need to be more selective.

Technology roadmaps:

- help identify duplication of effort.

- help long-range research (primarily academic research) to focus on industry's needs. 
- allow government to better enter into CRADAs with a particular industry by better defining the research agenda and implementation plan.

- help companies, industry associations, and consortia align their own internal programs.

- give targets for acceleration.

- accelerate the rate of building partnerships.

- provide the structure to get industry buy-in.

When selecting an industry and a technology for which you would develop a roadmap, you should start with domain-specific activities and extrapolate to an industry, i.e., look for mainstream applications. For example, in deciding what technologies should be developed for which roadmaps, SIA started with the semiconductor domain in the electronics industry. They further considered the device types needed for specific market applications. Finally, the roadmap addressed 11 common technology areas. 
Intentionally Left Blank 


\section{The SIA Technology Roadmapping Process}

A technology roadmap begins with a vision and leads to plans for action.

- For the semiconductor industry, the vision was global leadership and competitiveness.

- Getting to the future requires extending current technologies and developing major new ones.

- Two ingredients for successful technology roadmapping: intensive planning and cooperation.

In the early 1990s, the U.S. semiconductor industry realized it was in a battle for survival. Competition from Japan was stiff enough that the U.S. industry could lose not only its leading position, but possibly its very existence. Turning this dangerous situation into an opportunity for cooperation, members of the Semiconductor Industry Association (SIA) planned and carried out a technology roadmapping process in 1992.

The product of this process is widely regarded as an excellent example of a technology roadmap for industry. This study describes the process used by the SIA, so that it can be preserved and applied to other scenarios. The study is based on interviews with four people involved in the roadmapping process and its culminating workshop. (Names and functions are listed at the end of this section.)

The SIA Technology Roadmap was ambitious. It looked 15 years ahead in 11 key technology areas. This time horizon extends beyond the calendar of most planning groups in the industry, where typical product life is three years. A 15-year view, however, was what the roadmap planners concluded they needed in order to save their industry.

The remainder of this section describes the planning and implementation of the roadmapping process, including its culminating workshop. It also includes some specific lessons learned. 


\section{Interviewees}

The following people made themselves available for interviews. The information they provided forms the major part of the content in this document. They deserve thanks from the author and from others who will benefit from their experience.

- David Smith, Tech Transfer Director, SEMATECH (member of the Steering, Coordinating, and Logistics Committees for the SIA Roadmap Process and its workshop).

- Dr. Thomas Seidel, Chief Technical Officer, SEMATECH (member of the Steering and Technology Committees and chair of the Interconnect Working Group for the SIA Roadmap Process and its workshop).

- Sheila Endres, Tech Transfer staff member, SEMATECH (headed the Data Center at the SIA Roadmap Workshop and helped edit and produce the SIA Roadmap resulting documents).

- Emma Reams, Tech Transfer Director's Secretary (member of the support group for editing and publishing the resulting SIA Roadmap documents; also part of general support group).

\section{A note about acronyms}

Several acronyms appear frequently in the sections that follow. For convenience, they are collected and described here.

- SIA: Semiconductor Industry Association. U.S. industry banded together in 1977 to form this association to address their competitiveness in world markets.

- SRC: Semiconductor Research Corporation. SIA's first major initiative to address the industry's technological needs culminated in the formation of this corporation in 1981.

- SEMATECH: A joint industry/government consortium formed in 1987 to address fundamental manufacturing problems in U.S.-based industry.

- TWG: Technology Working Group. Workshop participants organized to develop technology roadmaps in specific technology areas. 


\section{Genesis of the SIA Technology Roadmap}

The idea of a technology roadmap for the semiconductor technology was conceived by Gordon Moore, Chairman of the Board at Intel and chair of the SIA Technology Committee. This origin was important because it meant that industry was at the center of the process. Other constituencies were also important; one conclusion from the SIA roadmap process is that the involvement of five parties is needed: industry, government, suppliers, customers, and universities. A technology roadmap could be described as a way of picking winners and losers among technologies. In such a process, the centrality of the private sector helps lend a market discipline to the proceedings, and guarantees that the people most directly affected will be intimately involved.

\section{Technology planning}

The 15-year period (1992-2007) spanned by the roadmap encompasses three levels of technology planning:

- straightforward extrapolation of current technology trends.

- extension of current trends to their reasonable limits. .

- development of major new technologies needed to reach beyond the capabilities of current approaches.

The SIA Technology Roadmap is actually 11 individual technology roadmaps for major technology areas. The 11 technology roadmaps address leading-edge, mainstream technology for integrated circuits. Device technology needs, anticipated for a broad range of applications, drive the roadmaps; both memory and logic requirements are incorporated. Typical characteristics of the range of product applications covered by this mainstream technology were identified in the roadmapping process, along with key integrated-circuit device characteristics and the cost distribution among principal waferfabrication functions.

\section{Vision statement}

A key ingredient of any technology roadmapping process is a shared vision towards which an industry can work. For the SIA Technology Roadmapping Process, this was the vision:

Semiconductor technology is the driving force for the information age. The U.S. semiconductor industry must maintain leadership in this enabling technology if our country's other information-based industries are to remain competitive in the global marketplace. To do this, serious technological and 
manufacturing issues must be confronted. We believe that additional progress against these goals can be achieved through improved teamwork among industry, academia, and government on pre-competitive technology issues.

The broad implications of this vision statement were addressed throughout the process and are reflected in the resulting roadmap.

\section{Committee structure}

A committee structure (Appendix 5) was established to develop and manage the roadmapping process, which included a workshop. The committee structure included the following committees:

- Steering Committee

- Technology Committee

- Coordinating Committee

- Framework Committee

- Implementation Committee

- Logistics Committee

\section{The Steering Committee}

The SIA Technology Committee created a Steering Committee to organize the roadmapping process. This new committee consisted of 20 top senior-level executives from industry and government, including national laboratories and SEMATECH. Two of the Steering Committee members were consultants who originally had been senior members of the semiconductor industry, but who were now hired to help the Steering Committee make this roadmap a reality. Costs of conducting the Steering Committee's operations were paid by various SIA member companies (more about financial arrangements appears on pages 21 and 22 .

Planning of the entire roadmap process flowed from this Steering Committee. The committee was created approximately six months before the workshop took place. Its members met for one day every three to four weeks.

Responsibilities of the Steering Committee consisted of identifying the high-level "whats" that had to happen in order for the roadmap process and workshop to be a success. The committee also marketed and promoted the roadmap process and workshop. 
The Steering Committee had two co-chairs: one from SRC and one who was a consultant from private industry. The consultant also chaired the Technology Committee and developed the Overall Roadmap Technology Characteristics chart (product characteristics and metrics over time that are referenced throughout the technology roadmapping process).

The Steering Committee members wanted a vision statement that was durable and attainable. This vision statement (previously quoted) became the foundation for building a single set of roadmaps that anticipate needed technological developments. It was generated over two meetings using input from work done by SEMATECH, SRC, and the Microtech 2000 Workshop (sponsored by the National Advisory Committee on Semiconductors).

\section{Other committees}

The Steering Committee created the committee structure necessary to plan the roadmap process and the workshop. The need for some of the committees was seen immediately. Others were added as the need arose. In addition to the Steering Committee, the structure eventually consisted of the following:

Technology Committee (not to be confused with the SIA Technology Committee): Two to three months after the Steering Committee was formed, it created the Technology Committee, whose members became chairs of the technology working groups (TWGs). The Technology Committee members prepared draft roadmaps for their individual working group meetings. They also met the day after each Steering Committee meeting, every three to four weeks.

Coordinating Committee: Created soon after the Steering Committee, the Coordinating Committee consisted of three people: the director of technology transfer for SEMATECH and two consultants. The committee's purpose was to provide the "glue" and forward energy - the continuity - needed by the roadmap and workshop planning process. The members did not usually meet in person, but had conference calls at least every week. This committee developed the strawman agenda for the workshop; the strawman was reviewed by the Steering and Technology Committees.

Framework Committee: The Framework Committee began about two months after the Steering Committee was created. It eventually consisted of ten people from industry, government, and academia. Two of the ten were consultants from private industry. Throughout most of its operation, however, the committee had just one consultant: the former head (retired) of IBM's Semiconductor Strategic Planning. This consultant developed the framework and cost targets, which drove the Technology Committee's development of individual technology roadmaps.

Implementation Committee: The Implementation Committee consisted of 21 people, 14 of whom were industry and government members of the Steering Committee. The additional seven were recruited from industry, government, and academia. The 
membership expanded after the workshop as the Steering Committee saw the need for more champions of implementing the roadmap. This group first met as a committee at the workshop, and then again a month after the workshop. The SIA is ultimately responsible for implementing the roadmaps, and each member of the Implementation Committee is also a member of the SIA.

Logistics Committee: The Logistics Committee was chaired by SEMATECH's director of technology transfer. It consisted of many workshop support people, such as the meeting planner, data center representatives, and "gofers."

\section{Planning the Roadmap Process: technology areas}

\section{Steering Committee planning}

The Steering Committee designed the overall roadmap process. It decided upon the 11 technical categories for technology roadmaps. The 11 technical areas tracked loosely with the organizational structures of both SEMATECH and SRC. A late addition to the list of technology groups was Environmental Safety and Health. Although the Steering Committee did not at first favor the addition, the Coordinating Committee felt it was important to have this thrust area represented by a technology working group. In the end, the consensus was that adding it was the right decision.

Technology areas designated by the Steering Committee:

- Chip Design and Test

- Lithography

- Materials and Bulk Processes

- Manufacturing Systems

- Process/Device/Structure CAD

- Equipment Modeling and Design

- Process Integration

- Interconnect

- Environmental Safety and Health

- Manufacturing Facilities

- Packaging 
Besides the Steering Committee's general oversight, there was a detailed project plan. The administrative details, however, were not viewed or discussed by the Steering Committee members. (According to one interviewee, the project plan was intentionally not shown to "the engineers" because they might try to redesign it!)

\section{Choosing members of technology working groups}

The Steering Committee selected chairs and co-chairs to head the 11 technology working groups. These people were selected on the basis of their leadership position at SEMATECH or SRC, or whether they already were chairs or co-chairs of technical advisory groups to SEMATECH. Usually the chairs were of director level. In some cases the chair was a less senior person at SEMATECH, such as a program manager.

The chairs and co-chairs of each working group were responsible for developing a list of potential participants for their group. They received guidelines from the Steering Committee to include people who were from SIA member companies, suppliers to the industry, academia, and government. The Steering Committee reviewed and revised each list, both adding and deleting names.

One purpose of the Steering Committee review was to make sure that all constituencies were represented. The theme behind the mix was to get the benefit of group wisdom from customers and suppliers.

The final lists consisted of senior technical managers: people who knew both the technical and the business elements. In addition, personality was important. The Steering Committee tried to create a balanced forum so that, as one interviewee said, "no one could get away with much." Some companies had a person in multiple groups, but no one company dominated any group.

A final control on the working group lists was a "no substitute" rule. The sum of this procedure was that the committee very carefully regulated who was invited and who was not.

\section{Preparing the working groups}

\section{Communication with group members}

Invitation letters to the people selected as working group members came from a high-level source: Gordon Moore, of Intel, who originally conceived of the project. This is an example of what one interviewee termed Moore's "stroking" in the right places within industry, government, and academia. 
The initial letter from Moore was sent three months before the workshop. Each invitee also received three more communications, co-written by the chair and co-chair of the appropriate technology working group. These communications were spaced three weeks apart and sent up to two weeks before the workshop.

The letters were a means to market the theme "participate in the future." The letters described the workshop itself as having the theme "complete, used, and implemented."

The first two communications from the chairs and co-chairs were executive summaries about the subject matter of each working group. The final communication was a document, approximately 25 pages, different for each working group, structured in such a way that attendees were forced to read it in order to participate in the workshop. (See Appendix 4 for an example of a communication sent to the Interconnect Technology Working Group Committee members.)

\section{Preparation by technology area chairs}

Chairs and co-chairs completed extensive prework before the workshop. The Steering Committee gave the Technology Committee (that is, the chairs of working groups) the responsibility of putting together an agenda for their individual technology areas. The chairs started with a set of expected outcomes, which had been developed by Gordon Moore and the SIA, plus a set of working group discussion guidelines prepared by the Steering and Framework Committees.

The chairs of the working groups were also asked to develop strawman roadmaps for their technology areas. (The technology roadmap format for this came from the SEMATECH roadmap format that is used within SEMATECH's Strategic Long-Range Plan; the Steering Committee modified this format for the SIA Roadmap Process and workshop.) The strawman roadmaps were presented and debated during the workshop to arrive at the final roadmap for each technology area.

Chairs and co-chairs were also responsible for developing a current review position paper about their technology area. This information (the approximately 25-page document sent to invitees two weeks before the workshop) consisted of an executive summary, an agenda of the working group meeting, a mission statement, a review of the technical status of the particular technology of a working group, and the strawman roadmap.

The position papers were reviewed by members of the Technology Committee; changes could be proposed and made. The strawman roadmaps were also reviewed, but changes were not allowed. 
Approximately two weeks before the workshop, the chairs of the working groups were given a template that detailed the requirements for the first-draft documents to be produced by each working group. At this point, the total size of the complete workshop document had been determined, and the templates included targets for the length of each section.

Each working group's document was to include information in these areas:

- Technology area identified and brief summary of what was meant by that technology.

- Current status of the technology area.

- The detailed roadmap, highlighting sub-areas.

- Critical factors determining whether the goals of the roadmap can succeed.

- The highest priority needs.

- A set of show-stoppers (factors that would, if not confronted, lead to failure of the roadmap).

- Areas of need not currently being addressed.

- Alternative approaches.

- Technical recommendations and summary.

- Implementation observations and recommendations.

Sixteen-hour days became the norm for the chairs and co-chairs of the working groups while preparing for the workshop. As a sample of work procedures, one chair said that he delegated about 40 percent of the work to his co-chair. He often validated his ideas through the use of task forces that he specifically established for this purpose. $\mathrm{He}$ felt that he needed more time in which to obtain certain numbers. Without the information, only limited discussion was possible in certain areas, and (at the date of the interviews for this report) these areas still needed resolution.

\section{Planning the workshop: logistics}

One characteristic of the workshop was that the physical arrangements (meeting rooms and food) were done quite carefully, while by contrast the financial arrangements were relatively informal. This section describes both of those aspects of workshop logistics and points out some of the benefits and drawbacks that resulted. 


\section{Financial arrangements}

No budget was assigned to the pre-workshop activities or to the workshop itself. Committee members' companies took turns paying for the meeting room and food costs of each of the committee meetings.

Member companies donated most of the required equipment, such as computers for the data center (described below). Participants were charged $\$ 300$ to attend. That sum included food for meals and breaks, but not hotel accommodations. A small amount of money was made on the workshop.

Individual companies paid their representatives' travel costs. Document printing costs were divided among SEMATECH, the Semiconductor Industry Association, and the Semiconductor Research Corporation.

Committee members generally were not paid for their service. The exceptions were consultant members of the Steering Committee.

Participants (or their companies) readily paid the workshop fee because the workshop was seen as a chance to influence the future of the industry. The participants wanted to have their names on the attendees list, and some have since listed their workshop participation on their professional resumes.

Before the registration fees were processed, SEMATECH set up an account in case the need arose to pay for something. Some participants paid their fees before the workshop, and some at registration.

\section{Accommodations and food arrangements}

\section{Meeting planner}

The physical details of planning the workshop were vital to its success. Among the important lessons of the SIA experience is that seemingly mundane matters can strongly influence the outcome.

The meeting planner proved very important. This person came from the SEMATECH staff and, among other things, was instrumental at the workshop in getting people where they needed to be at the appropriate times. She also helped with transportation matters, food, and hotel arrangements. It was a demanding job: her hours at the workshop were from 2:30 a.m. to 10:30 p.m.

Every detail was centered on structuring the meeting for success. To make that attitude work, an empowered team was necessary for handling the details. 


\section{Hotel service, staff, and food}

The workshop was held at the Harvey DFW, Irving, Texas. This is a hotel whose performance was known to the team, because SEMATECH had held many successful forums there. SEMATECH had established a professional rapport with the hotel staff.

Before the workshop, Logistics Committee member David Smith met with the hotel staff and explained the level of customer service he was looking for. He let the staff know about the kind of people they would be dealing with, the amount of stress these people would be feeling, the long hours they would be working, etc.

Steering Committee members spent time at the hotel a month before the workshop so that they could become familiar with the rooms, the food, and the staff.

Government rates were available at the hotel. Attendees were also notified of other hotels in the vicinity in case they preferred to stay elsewhere.

The food for the workshop was carefully selected. Variety was very important. Location of the meals was also varied. Special events were included, such as ice cream sundae breaks and a cookout on the last day of the workshop, with a tent set up outside the hotel. The team made arrangements for extra cocktail hours. There was always plenty to eat and drink, although the team also made sure that the food was light so that the attendees would not go to sleep in the meetings.

\section{Meeting rooms}

Several specific arrangements were made for the meeting rooms and other workshop-related support:

- Telephones were in all the working group meeting rooms. Each chair had the telephone numbers of the committee members and the data center, should he/she need assistance.

- In the large group meeting room, large screens were used to display vugraphs and other presentation material. This room also had microphones.

- Five small meeting rooms were booked for impromptu meetings. They probably could have used more. Another alternative would have been to put each working group chair in a suite (picking up part of that cost for them), so that they could have used their suites for the impromptu meetings and late night work. 


\section{Data center}

A data center was set up at the hotel to provide support in word processing, writing/editing, and graphics. The center included computers and staff people, plus provision for communication.

Computer equipment consisted to 20 PCs and UNIX workstations on loan from various member companies. The equipment would have cost $\$ 7,000-\$ 10,000$ in 1993 if leased for a week. Balanced against the cost savings, however, were some problems with software incompatibility and with computers that did not work.

The data center also had numerous telephone lines to communicate with workshop participants elsewhere. A final item was a photocopier rented for the workshop. Interviewees describe this as the most useful machine they had.

Staffing the data center were several writer/editors and five word processing and graphics staff people. In addition, temporaries were hired to act as "gophers." They became indispensable at copying and running errands.

Each writer was assigned to two or three working groups' chairs. It was the writers' responsibility to close the loop, making sure that nothing was forgotten in documenting the results of each day's session. As one minor but critical detail, they made sure that all computer disks were marked with the proper file names.

The chairs used the graphics people to make vugraphs for the normalization sessions and the summary session. The graphics people became swamped with work when the chairs tried to prepare for their final presentations on the last day of the workshop.

\section{Conducting the workshop}

The workshop had a two-part charter:

- Evaluate likely progress in key areas relative to expected industry requirements and to foreign competition.

- Based on this evaluation, identify how available resources might best be used to ensure that the U.S.-based semiconductor industry would have the necessary basic technology and technological options for success in the competitive world market.

The workshop was a three-day event that began on Tuesday, November 17, 1993, and ended (for most participants) on Thursday, November 19, 1993. 
This section describes how the workshop was conducted. The numerous facets of the workshop are here organized into format, facilitation, and other communication/ interaction procedures.

\section{Format}

The workshop opened with a plenary session led by Gordon Moore, the general chair. The large group then broke into 11 smaller technology working groups, whose sessions were attended by members of these working groups. Other workshop participants attended committee meetings.

After the first full day, there were half-day normalization sessions in which each chair made a 15-minute presentation about his or her group's progress. A summary session closed the workshop, with each chair giving a presentation. The Coordination Committee provided the format for these presentations.

The working groups were locked together from 7 a.m. until at least 10 p.m. every day. One group ran into difficulties and often had to work until 2 or 3 a.m. to complete each day's work.

This working and presentation schedule was a demanding one, especially for the working group chairs. Each chair spent late nights preparing presentation material for the following day. They were also putting each day's information on a computer. This daily compilation saved them time at the end of the meeting, however, when they put together their documents.

The chair of each working group developed his or her own process for achieving the expected outcomes of the working group meetings. The only process requirement was that certain progress be made each day. Any recommendations by these working groups were to be made under the ground rules that no new organizations should be created and no significant increases in industry investment were to be expected.

Working group discussions led to identification of the following summary items:

- Working group roadmaps.

- Pervasive technology competencies, which span individual technology areas.

- Issues affecting the technology environment.

- Key technology challenges.

The information produced by the working groups was to contain enough detail to satisfy technical people while remaining understandable by nontechnical audiences. 


\section{Facilitation}

To assist the working groups, the Steering Committee selected six facilitators from SEMATECH's facilitator group, which is maintained for the many forums the consortium hosts. Some SEMATECH facilitators were on assignment from various member companies.

The facilitators joined the process late, after it became apparent that some of the working groups would probably have problems during the workshop. Responsibilities of the facilitators included knowledge of facilitation procedures, scribing, handling conflict, maintaining the pace of the meetings, and driving the groups to closure.

The strongest need for facilitation occurred in the manufacturing systems working group, whose many problems led to the assignment of two facilitators. At one time, this group was split into three camps. Besides the facilitators, members of the Coordinating and Framework Committees spent much time with this group trying to help it resolve its problems.

Some working groups did not use a facilitator. In those cases, the chairs or cochairs took on the facilitation responsibility.

\section{Other communication/interaction procedures}

Pagers and/or radios were worn by Coordination Committee members at all times. A Framework Committee member, located in a specific meeting room, was always available for consultation.

Gordon Moore stayed for the entire workshop. The committee members made sure that they had things scheduled for him to do. He was able to meet with many industry leaders and attend committee meetings.

At the large-group events, each attendee was assigned a seat. During some lunches and dinners, attendees were encouraged to mingle and address cross-cutting issues. Otherwise, each working group stayed together from morning until night every day.

The ground rule for each working group was that the sessions must be entirely needs-based. To help keep the working groups on track, a "penalty" procedure was used. Crystal bowls were put in each group's meeting room. If an attendee brought up something or made a comment that was non-needs-based, he or she was required to put a certain dollar amount into the crystal bowl. At the end of each day, the groups decided what they wanted to do with the money. This trick went a long way toward keeping the working group meetings focused. 
No reporters were allowed at the workshop, and no press releases were made. Still, the press found out about this workshop and it showed up on the front page of a Dallas newspaper.

\section{Preparing draft conclusions, recommendations, and roadmaps}

While most other participants ended the workshop on Thursday afternoon, the working group chairs remained through Friday to continue drafting workshop documents. Each chair had produced a draft of his or her working group's information by the time they left the hotel on Friday afternoon. Disks containing these drafts, with file names carefully marked, were taken to SEMATECH for editing into a single document. This flash draft was available for Steering Committee members by the following Tuesday 20 copies were mailed to them. This allowed them to work the implementation issues while working the workshop issues.

The flash draft given to the Steering Committee members was the document eventually published as Workshop Conclusions. It was written for the Washington audience involved in funding and policy issues. The Washington audience was one consideration in working quickly to get the workshop conclusions into draft form.

After the initial draft of conclusions, Sheila Endres, Senior Editor at SEMATECH, was able to begin putting together the technical sections of the document that would be published as Workshop Working Group Reports. It was written primarily for the technical audience. She used faxing and e-mail to fill holes and clean up the workshop output.

A retired senior industry member (previously from Texas Instruments) was hired after the first draft was produced to provide a fresh set of eyes to the workshop output. This person had not been associated with the workshop but was familiar with the Washington political scene. He also knew the technology very well. He was able to point to missing information and to add linkages between absent passages.

\section{Implementation}

The SIA is responsible for the actual implementation of the workshop recommendations and resulting roadmaps. Many Steering Committee members were also part of the Implementation Committee and of SIA.

In each of its meetings, the SIA Technology Committee reviewed the results of the workshop and the action items that came from it. Many companies and organizations that were involved in the workshop have brought their people together to consider the desirability of proprietary $R \& D$ programs focusing on critical needs and timetables. 
With the guidance offered by the consensus roadmap, it was hoped that government-funded programs and those performed in government labs could similarly be reassessed to address roadmap needs that were beyond the industry's capabilities. The SIA also hoped that any redirection of government $R \& D$ from defense to civilian or dualuse needs would be accomplished with the needs of this roadmap in mind.

The SIA published $A$ Seniconductor Technology Agenda, which amplifies these ideas and provides a basis for industry-government cooperation in planning and executing programs to meet roadmap objectives.

The roadmaps are to be examined regularly. There were plans to reconvene a workshop every couple of years to keep them current and vital. The National Technology Roadmap for Semiconductors occurred at a Roadmap Workshop held in June 1994, in Boulder, Colorado. This revision also extends the timeline one more generation beyond that of the 1992 Roadmap.

\section{Lessons learned}

In conclusion, there are a number of lessons learned from this experience. This section presents those lessons, divided into several categories.

\section{General}

- Take as much of the politics out of the process as possible. The committees found themselves worrying about how many times a meeting was held at a particular location or whether one company was represented too many times on too many committees or working groups.

- Notify participants of their expected involvement according to the kind of position they hold with their company. Experience with this group of people revealed that senior people on the Steering Committee were the most flexible because they travel the most. Technology Committee members often had production responsibility at their companies and thus had less flexibility. Invitees were notified of workshop dates approximately three months ahead of the workshop.

- Keep realistic bounds on the numbers of participants. Two hundred people was the maximum that could have been handled at this workshop with 10-14 working groups. This is about as large as can successfully be done. However, the 1994 Roadmap Workshop had almost 300 participants. This was a more structured process, revising an existing roadmap. 


\section{Technical information}

- Make sure all the needed data is available for the workshop. Its absence may limit discussion in certain areas and consequently delay resolution.

- Define terms at the beginning of the workshop. Problems developed during the editing stage because many people used various terms to mean different things.

\section{Logistics}

- Make sure the data center is well-focused. When establishing such a center, choose its functions and organize accordingly. A much more focused data center would have benefited this workshop.

- Include enough documentation/communication support people. The workshop needed more documentation people who were creative and more communication support types, including good typists and more graphics people.

- In the data center, include people who understand different computer platforms. A lack of such people was a problem at the workshop.

- Have several qualified people who can provide computer support. They and the workshop organizers should be prepared to do anything required to keep the computers operational.

- Consider renting computer equipment and hiring someone dedicated to setting it up and supporting it. Because people participating in the workshop supplied the equipment, there were too many different kinds of equipment and support. In addition, much of the equipment did not work.

- Be careful of the software packages used - they need to be supported by the company that will be producing the resulting document. One should be able to directly convert from one package to another.

- Hire a company in the city where the workshop will be held to make all the arrangements for the workshop. It's very difficult making meeting arrangements from a distance.

- Bring key people into the process early. The workshop would have benefited by including some key people earlier in the process. For example, the data center manager was pulled in only one month before the workshop. In comparison, the meeting planner was pulled in four months before the workshop and consequently had more time to prepare for the workshop. 


\section{Interfaces}

- Make sure participants know what the data center people can do. The chairs knew, but didn't communicate this to their working groups.

- Give editors plenty of time to familiarize themselves with various roadmaps submitted by each working group. They need this time in order to come up with a consistent roadmap format. Although the working group chairs were given a roadmap format to follow, some varied the format by using different legends, or because their technology area didn't lend itself to the original roadmap format. It took about one month after the workshop to get this problem resolved.

\section{Refining the Technology Roadmapping Process}

Based on this and other roadmapping work, more research was conducted on technology roadmap development, resulting in a more refined process. The results of that research and a description of the process may be found in the report SAND97-0665, entitled Fundamentals of Technology Roadmapping. 


\section{Appendix 1. SIA Technology Roadmapping Process - Committee-Structure Viewpoint}

\section{A. Necessary preexisting conditions}

- Perceived need for roadmaps.

- Someone with a vision; a high-level, respected sponsor.

- Industry association/consortia infrastructure in place.

- Must not have adversarial conditions between the producers and the suppliers; if so, you will have a marginal condition.

- The focus around which to make decisions about selecting appropriate technologies must be based on their ability to meet a need.

- Selection of appropriate technologies (e.g., national critical technologies) and industries.

- Specific boundaries defined.

- Involvement of industry, government, suppliers, customers, and academia.

\section{B. Industry association/consortia should establish Steering Committee six months before roadmap workshop date}

- Include approximately 20 senior-level executives from industry and government.

- Include some independent consultants.

\section{Steering Committee assumes many responsibilities (identifies high- level "whats")}

- Develop a consensus vision for the future of a specific industry; what time frame that vision will cover.

- Identify expected outcomes for the workshop.

- Macro-design the overall workshop.

- Select chair of overall workshop. 
- Market the workshop.

- Select technology areas for roadmaps.

- Establish a committee structure.

- Select chairs and co-chairs of technology areas/working groups.

- Provide guidelines for selection of attendees to the chairs.

- Make final selection of attendees.

- Determine roadmap format to be used by chairs.

- Approve overall technology roadmap to serve as guide to chairs.

- Provide guidelines for roadmap development and communications to attendees.

- Determine how workshop costs will be covered.

- Determine number of facilitators needed and make selection.

- Provide a template to the chairs that details the requirements for the first draft documents to be produced by each working group.

\section{Steering Committee establishes committee structure}

- Coordinating Commitfee: establish soon after Steering Committee.

- Framework Committee: establish one month after Steering Committee.

- Implementation Committee: establish one month after Steering Committee.

- Technology Committee: establish two months after Steering Committee.

- Logistics Committee: establish two months after Steering Committee.

Coordinating Committee responsibilities:

- Consists of chairs of three committees - Logistics, Framework, and Technology.

- Balance the Steering Committee; provide additional wisdom, glue, and forward energy.

- Resolve problems in the working groups during the workshop. 
Framework Committee responsibilities:

- Develop overall roadmap and other data tables necessary for the workshop.

- Use respected consultant from industry.

- Make itself available during the workshop to answer questions about overall roadmap characteristics.

Implementation Committee responsibilities:

- Should consist of many Steering Committee members.

- Establish responsibility for overall implementation.

Technology Committee responsibilities:

- Consist of chairs and co-chairs of each technology area working group.

- Develop list of attendees - final approval by Steering Committee.

- Three months before the workshop, invite attendees to the workshop; keep them informed.

- Develop draft roadmaps for each technical area working group.

- Design extensive packages of information and communications to be sent to attendees.

- Develop process(es) for achieving expected outcomes in each working group.

- Deliver presentations at workshop.

- Write first draft document of working group results.

- Follow up with data center to finalize document.

Logistics Committee responsibilities:

- Create at least four months before workshop date.

- Select a meeting planner - an absolute necessity. 
- Select a hotel; make food arrangements.

- Establish a data center.

- Arrange for all the equipment that will be needed (computers, copiers, pagers, telephones, radios, microphones).

- Determine seating arrangements; number of meeting rooms necessary for large and small group breakouts.

\section{E. Workshop commences}

- Attendees register for workshop and pay fee.

- Workshop membership covers all constituencies.

- No substitute rule encourages commitment.

- Chair opens the workshop.

- Hold plenary, normalization, and summary sessions with large groups.

- May take three days, from 7 a.m. to 10 p.m., to obtain necessary information.

- Each working group should be headed by a chair; sometimes a facilitator should be present to handle difficult groups.

- Keep working groups together as much as possible; some cross-team networking may be conducted at appropriate times.

- May use different process in each working group to fulfill progress requirements for each day.

- May use cheap tricks to obtain appropriate behavior and progress.

- Before departure, obtain first drafts (conforming to requirements) for general document, and data files for draft of technical document.

\section{F. Document production}

- Establish a data center for the workshop and for document production.

- Identify needs of committee members, chairs of working groups, and attendees.

- Make available appropriate computer equipment, software packages, and translators. 
- Supply computer hardware and software support.

- Have available the appropriate types of data center staff (typists, graphics, editors, writers).

- Label each disk with a file name; make sure it doesn't get lost.

- Establish a process for reviewing drafts and finalizing documents.

- Share production costs.

\section{G. Implementation}

- Industry association or consortia is responsible for overall implementation (workshop recommendations and roadmaps).

- Market to stakeholders to ensure continued support and distributed leadership in aligning investment with roadmap.

- Some members of the Steering Committee should also be on the Implementation Committee to ensure continuity.

- Regularly examine roadmaps.

- Reconvene a workshop every couple of years to keep roadmaps current and vital. 
Intentionally Left Blank 


\section{Appendix 2. SIA Technology Roadmapping Process - Functional Viewpoint}

\section{A. Determine necessary preexisting conditions.}

B. Provide leadership/sponsorship.

- Provide leadership, a vision for the future of a particular industry.

- Market the need for a technology roadmap; solicit participation in the process.

- Chair committees.

- Industry association/consortia provides support.

C. Establish high-level "whats" that need to be done.

- Involve senior-level executives from industry and government.

- Establish consensus vision, time frame for roadmap.

- Develop overall roadmap and any other necessary tables; identify technology areas for which roadmaps will be developed.

- Identify expected outcomes of the workshop.

- Market the workshop.

- Develop project plan for the effort.

- Macro-design the workshop.

- Select chairs of committees/working groups.

- Provide guidelines for selection of attendees.

- Approve final list of attendees.

- Develop template for outputs required from workshop.

- Determine how costs will be covered.

- Resolve problems in the working groups. 


\section{Establish detailed "whats" that need to be done.}

- Using guidelines, develop list of attendees.

- Chair working groups.

- Develop communication packages for attendees.

- Develop roadmaps for each technology area.

- Develop processes for each working group to achieve expected outcomes.

- Make presentations at workshop.

- Prepare working group report documentation.

\section{E. Establish "how" it is going to be done.}

- Select a meeting planner.

- Select a hotel; make food arrangements.

- Make arrangements for necessary equipment.

- Determine seating arrangements.

- Determine necessary staff support; select appropriate staff.

- Develop methods for handling payment of expenses and for collecting workshop fees (should there be any).

\section{F. Workshop commences.}

- Register attendees.

- Open workshop.

- Hold large coordination and small group working sessions.

- Determine length of time for workshop (number of days and hours worked).

- May use different process in each working group to fulfill progress requirements for each day.

- May use cheap tricks to obtain appropriate behavior and progress. 


\section{G. Document production.}

- Identify needs of workers and attendees.

- Establish a data center for the workshop and for document production.

- Make available appropriate computer equipment and software packages.

- Provide computer hardware and software support.

- Provide appropriate levels of data center staff support.

- Establish process for reviewing drafts and finalizing documents.

- Share production costs.

\section{H. Implementation.}

- Industry association or consortia assumes responsibility for overall implementation.

- Recruit some of the same senior-level executives who identified the high-level "whats" to assume implementation responsibilities.

- Regularly examine roadmaps.

- Reconvene a workshop every couple of years to keep roadmaps current and vital. 
Intentionally Left Blank 


\section{Appendix 3. Frequently Asked Questions about Technology Roadmapping}

The Semiconductor Industry Association (SIA) technology roadmapping workshop of 1992 provides experience-based answers to some of the questions frequently asked about technology roadmapping. Questions can range from quite general to quite specific.

This section presents several of the questions often raised and provides one or more responses to each question, in the light of the SIA workshop. Other relevant roadmapping experiences observed by Sandia's Strategic Business Development organization are presented as well.

Can we make the process less complicated and still obtain the same results?

- Yes, in some industries you can use a less complicated process and still obtain similar results. For example, take the U.S. Display Industry. It has only four or five players and about 20 subsuppliers. They're not market leaders. In fact, they don't have collectively 25 percent of the total market. They're very contained with a market driver that says "I have to cooperate." In their case, you could probably conduct a survey regarding technology needs and develop a roadmap.

- No, in the case of competitive industries, a less complicated process would not work and still obtain the same results. In a robust marketplace with lots of players and sub-tier players, the richer the structure, the harder it is to accomplish agreement about a technology roadmap. There's a higher degree of competitiveness in which you have to contend.

What's in it for industry to participate in a technology roadmap workshop? If everyone uses the same technologies, what allows each company to be competitive?

- A company is competitive by being robust. What happened at the SIA Technology Roadmap Workshop is no different than presenting papers at an industry conference. The difference between each company is in how they implement the technology in the marketplace. The downside is that this does put foreign competitors on the same technology basis as U.S. competitors. However, the Japanese, especially, have a way of finding out this information anyway. These workshops allow Americans to share information. This is something they normally do poorly. 
Was there an assumption made about what will be needed in 15 years?

- Yes, there was an assumption made about what will be needed 15 years in the future. It was a learned guess. That's one of the reasons why a strawman roadmap was developed. Nothing that was developed previous to the workshop survived 100 percent.

Would fewer technologies speed up the process?

- Having to develop technology roadmaps for fewer technologies would not have speeded up the process. The determining factor is the number of groups that would be manageable, not necessarily the number of technologies. If the SIA Roadmap Workshop could have easily incorporated 500 people and 20 working groups, it would have.

Can a process be developed fiom a finctional perspective rather than by a committee structure?

- The process could be developed from a functional perspective rather than by a committee structure. However, the committee structure allows for more buy-in. There are lots of politics involved in this endeavor. The committee structure helped keep them to a minimum. The committee structure also helps generate enthusiasm. Participation on the committees became part of peoples' resumes. It's in the best interest of all involved to see the endeavor succeed. The more acceptance there is, the more successful it will be.

What are the benefits of top-down us. bottom-up?

- With a top-down process, the boundary conditions can be established. This allows for individual technology roadmaps to be developed within those boundary conditions. With a bottom-up process, the boundary conditions would not be known, resulting in the individual technology roadmaps not matching up and with so many holes in them that it would be difficult to then develop an overall roadmap. 
Can you assume an industry that is not as well defined/developed, with common standards, can pull this off? Does everyone use the same mamufacturing processes? Are they fairly conmon and understood across the industry? Is this a prerequisite to developing technology roadmaps?

- The needs for a technology can span multiple processes. Needs for control span dozens of process flows. When developing technology roadmaps, the real needs of a particular industry must be the same. The tools they use are often similar; the same tool can be used in multiple industries, but the process flows are different. For example, in the glass bottling industry, each company still needs things to form glass, to do quality on glass, and to achieve smoothness of the glass, etc. Each company may use similar tools to accomplish these things, but have different processes for accomplishing them. Therefore, common standards are not the problem, nor a prerequisite for developing technology roadmaps.

Is a group event appropriate? Are there other means (a survey?) to obtain the same results?

- The workshop is absolutely necessary for the success of the endeavor. It's been used now with the semiconductor industry and the textile industry. People who have to perform believe and buy-in. Consequently, those people participating in the workshop develop ownership for the results; they have the opportunity to - network among each other, and their participation gives credibility to the resulting roadmaps. If these things did not occur, implementation would be difficult to impossible.

Are roadmaps great for the industry and the companies? It puts all companies on the same basis. What would drive them to go through with this? What is the economic cost benefit?

- The cost benefit is that there is no duplication of resources. It allows companies to focus their energies. An informal look at the producers reveals that they are realizing a 10 to 25 percent cost savings in their internal $R \& D$ costs.

They can use this savings to look at other things that they might not have had the money for in the past. They now know where to focus and to hedge. It may actually result in more innovation.

What do you see as the labs' role (SNL's) in developing technology roadmaps?

- Major roles for the labs include a participant role and strong motivator role. Other roles might include catalyst, ambassador, consultant, and facilitator. The main point to remember is that for a roadmap to be used, it has to be driven by industry. This is the perception of the people who have to perform to the roadmaps. 
Intentionally Left Blank 


\section{Appendix 4. Interconnect Working Group Pre-workshop Communication}

\section{A. Outline of SIA Roadmap Activity}

The following letter to the SIA Interconnect Committee is from Tom Seidel:

Nov. 11, 1992

Dear SIA Interconnect Committee Member:

This is the last communication on the SIA Roadmap activity prior to your participation in Dallas on Nov. 17-19 at the Harvey Hotel (Irving). Attached are working documents:

Proposed Agenda

Interconnects Workshop Roster

"SIA SEMICONDUCTOR TECHNOLOGY WORKSHOP"

Framework Needs (Provided by Steering Comm.; Obi Oberai)

Executive Summary Interconnects (Working Group Mission)

Plenary Session Summary (kick-off position of Interconnects)

INTERCONNECT SIA PROCESS - this is "our" W.G. process.

Interconnect Strategy

Comments on the Strategy: Definition of Primary Needs

Cost Estimate (current process flow)

Max \# Interconnects $/ \mathrm{cm}^{2}$ Fig. 1

Delay Strategy, RC delay; Fig. 2

Current Density; Fig. 3

Lumped Stress Parameter; Fig. 4 (to come later)

Generic Solutions

Specific Solutions

Specifications

Core Competencies

Key Interconnect Issues

CMP, Interconnect

Reliability, Equipment Cost of Ownership

Plasma Etch

Revisited (Integration/streamlining) Issues

Thermal Limit SHOW STOPPER Issue 
Bibliography

WG Guidelines / Industry Overview

Badih El Kareh's scaling assumptions (later)

B. Case, Microprocessor report; benchmark thermal Eng.

M. A. Korhonen, et. al., Stress Induced Migration

The prework suggests there are at least two potential show stoppers:

dense, high frequency logic leads to thermal-packaging limitations, and the role of stress migration failures. However, there are literally dozens of critical success

factors. Please review this material in preparation for a productive workshop.

Looking forward to working with you,

Tom Seidel 
B. Interconnect Working Group Agenda for Workshop

\section{SIA INTERCONNECT WORKING GROUP AGENDA}

Tuesday, Nov. 17, 1992

8:00

Plenary Session

11:00

Mission, Objectives, Vision of the WG

Tom Seidel

11:20

Introductions

All

11:40

Interconnect Strategy, Workshop Needs

(Needs Examples, set stage for outputs)

Tom Seidel

Note: We will collect critical factors for success throughout the working meeting.

Joint Lunch

$1: 00$

Generic \& Specific Solutions (Films)

Ron Schutz

Comprehension of Limits

(Strawman Responses, develop aligned position)

Generic \& Specific Solutions (Etch)

Lou Katz

Comprehension of Limits

(Strawman Responses, develop aligned position)

4:30 Break

5:00 Related Elements .. Specifications, Gaps Tom Seidel

6:00 Joint Dinner Summary of Future Vision All (Limitation of Vision)

7:00

New Architecture(s)

Mike White

8:00

New Materials

J. Turnbull

9:00

Summary Position for Plenary

All

(Apparent showstoppers, critical success factors)

$9: 15$

End Tuesday Work 
Wednesday, Nov. 18, 1992

8:00 Plenary Session

11:00 New Engineering, Cost

Bob Havemann

12:00 Joint Lunch (Discuss other WG's output)

All

Feedback to, Check Point with Other WG's

Lou Katz

1:00 Rev Issues, Recommendations

Ron Schutz

(Implementation Plan)

3:00 Customer-Supplier Check Point

All

4:00

Draft First Recommendations

("10 pager" Preliminary report)

All, Chairs

$6: 00$

Dinner

$7: 00$

Repeat Process Cycle with updates

7:00

Prepare Draft of Output ("10 pager")

Tom Seidel, Group

8:00

Review Draft of Output Schutz, Katz

Review Plenary Statement for Thurs

(20 minutes +10 for discussion)

9:00 End Wednesday Work

Thursday, Nov. 19, 1992

8:00 Plenary Session

12:00 Joint Lunch

1:00 Work Final Draft of "10 pager,"

Draft of extended report.

All

5:00

Adjourn

Friday, Nov. 20, 1992

Chairs are to coordinate across WG's and edit reports. 


\section{Working group discussion guidelines}

1. Prepare Working Group Members for discussion using the strawman mailing before the meeting.

2. Urge Working Group Members to prepare a one to two foil summary of talking points.

3. The Working Group discussion should be needs-driven, not solutions driven, and cover the full range of enabling technologies.

4. Workshop discussion should take place in two phases: (1) reach agreement on a roadmap that represents world class for your working group's area; (2) suggest implementation possibilities consistent with the roles and capabilities of industry consortium, government, and academic resources.

5. Expect to have to coordinate with other, related working groups - Working Group scope and specific needs will be circulated to all Working Group participants.

6. Considerations must extend beyond purely technical issues to embrace cost, producibility, reliability, and ...

7. In addition to the view of semiconductor producers, customer, supplier, and equipment makers must be brought into play.

8. Output of the workshop is to be summarized in roadmap charts, summary document and implementation questionnaire as defined by the framework and implementation committees.

9. Progress of the discussions will be summarized in the middle and at the end of the workshop.

10. The report of the workshop is intended for the use of the SIA in planning its coordination activities for U.S. manufacturing technology development. 
Intentionally Left Blank 
Appendix 5. SIA Technology Roadmap Workshop Committee Flowchart Diagram 
Intentionally Left Blank 


\section{SIA TECHNOLOGY ROADMAP WORKSHOP}

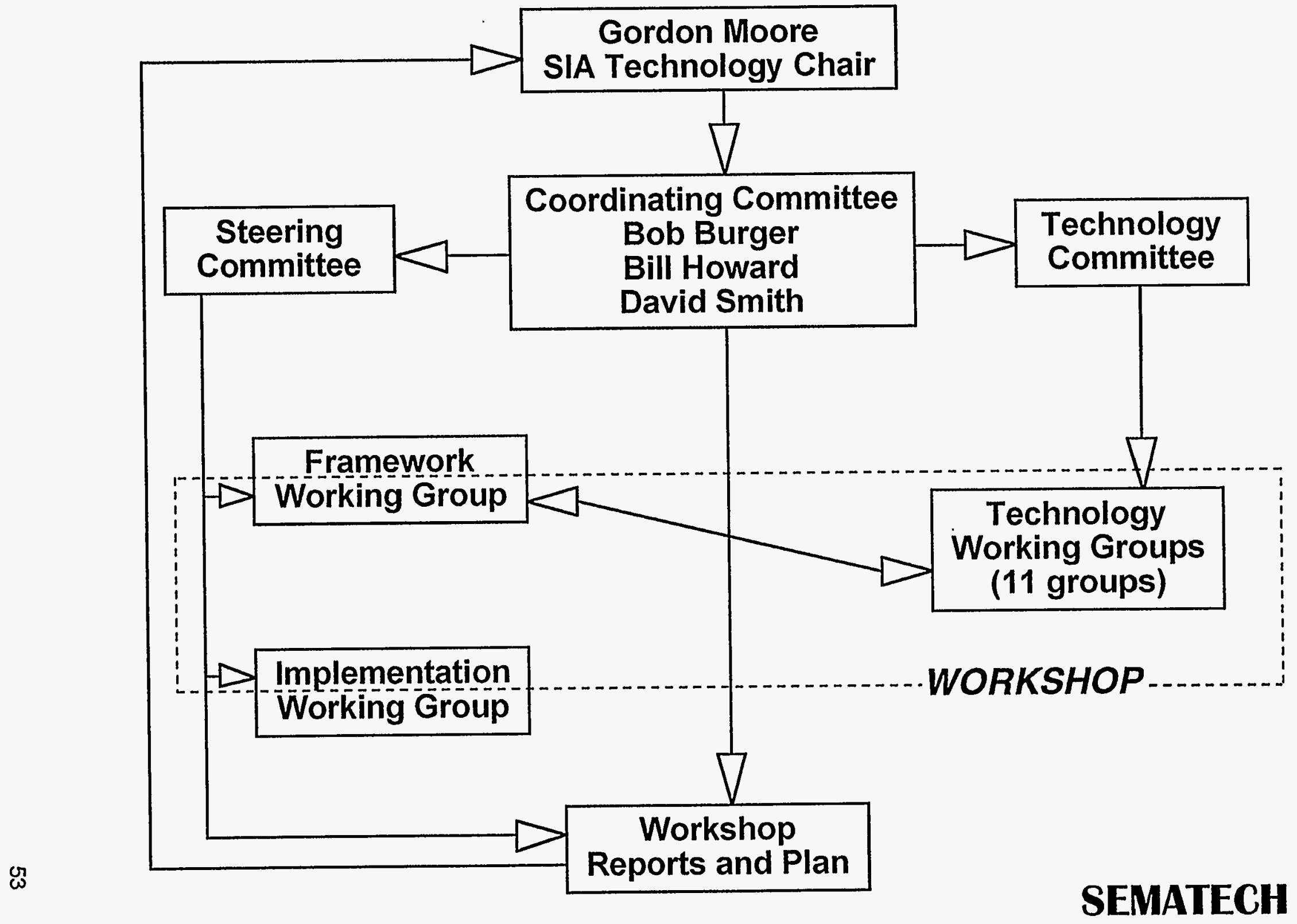




\section{DISTRIBUTION}

1 MS 0149 Dan L. Hartley, 4000

10160 Virgil Dugan, 4500

10340 Wendy R. Cieslak, 1832

10342 Richard J. Salzbrenner, 1805

10431 Samuel G. Varnado, 6500

10457 Heinz W. Schmitt, 2000

10457 J. Stephen Rottler, 2001

10513 Robert J. Eagan, 1000

10710 Nancy B. Jackson, 6210

$10710 \quad$ Alan P. Sylwester, 6210

10752 Marjorie L. Tatro, 6219

10762 Greg A. Mann, 5823

$1 \quad 1002$ Patrick J. Eicker, 9600

$11071 \quad$ James L. Jorgensen, 1202

$10 \quad 1378$ Olin H. Bray, 4524

301378 Marie L. Garcia, 4524

$1 \quad 1378$ Shanna Narath, 4524

1 - 1380 Warren D Siemens, 4200

11380 Marshall Berman, 4271

11434 James L. Jellison, 1803

11435 Harry J. Saxton, 1800

19001 Thomas O. Hunter, 8000

19017 Randy C. Christman, 8501

19405 Duane L Lindner, 1809

19018 Central Technical Files, 8940-2

50899 Technical Library, 4414

20619 Review \& Approval Desk, 12690 For DOE/OSTI 